\title{
Metapsicología freudiana, acto cinematográfico
}

\author{
Misterios de un alma | Georg Wilhelm Pabst | 1926
}

\section{Olivier Douville*}

\author{
Psicoanalista, Profesor titular universitario, Laboratorio CRPMS, Paris Diderot
}

Recibido: 4 de febrero 2018; aceptado: 20 de abril 2018

\begin{abstract}
Resumen
Después de haber presentado las circunstancias del rodaje de la película Misterios de un alma de Pabst, el autor explica la actitud hostil de Freud respecto a esta película que, sin embargo, tuvo tanto éxito.

Más allá de las reservas o el desinterés que mostraba Freud hacia las formas más avanzadas del arte de su tiempo, su teoría de los procesos psíquicos puede ser muy conveniente para describir lo que el cine trae de nuevo a la situación de la imagen. ¿Qué pasa hoy con esto? ¿Cómo el cine lleva la marca del fin de las grandes narraciones y de las violencias de la historia? Psicoanálisis, semiología y ciencia del movimiento pueden unirse para hablar del cine, no sólo como un arte narrativo sino también como un arte que va a representar en su propia gramática las heridas infligidas a lo imaginario colectivo y a la capacidad de soñar.
\end{abstract}

Palabras Clave: Cine mudo | Historia del psicoanálisis | Metapsicología | Narración | Trauma

Secrets of a Soul

\begin{abstract}
After having presented the circumstances of the shooting of "Mysteries of the soul" by Pabst, the author explains the hostile attitude of Freud towards this movie which is actually quite well done. Whatever the absence of interest or reservations Freud might have had for the most advanced forms of art of his time, his theory on the unconscious processus could fit quite perfectly to describe what the cinema invents image wise. Where are we today? In what way do the movies carry the traces of the end of the great collective fictions and violence in history? Psychoanalysis, semiotics and motion science could join to treat movies not only as the narrative art, but also as an art which will articulate in its grammar, inflicted wounds to the common imagination and the ability to dream.
\end{abstract}

Key Words: Silent cinema | History of psychoanalysis | Metapsychology | Narration | Trauma

Partamos de este punto: en la mitad de los años 20, exactamente en el año 1926, se gesta el proyecto de filmar una cura psicoanalítica. Esta tarea es confiada a un personaje ambiguo, dudoso, bastante apasionante y a menudo desesperante llamado Georg Wilhelm Pabst. Se podría ver en él la ilustración misma de la neurosis de fracaso; se destacó en films bastante libertarios y ganó una pequeña reputación dirigiendo films antinazis antes de ser tomado y afamado por los nazis. Inventó para el régimen nazi un film sobre el alquimista Paracelse, que no es más que un apólogo bastante apestoso del nacionalismo alemán, cambia una vez más de bando e intenta exorcizar los demonios del nazismo filmando su versión del Proceso de Kafka en el que restauraba un gueto judío.
Pabst, en 1926, es un Pabst que comienza a tener buena reputación pero que no ha ganado aun la audiencia que le asegurarán más tarde sus películas con Louise Brooks y en particular La calle sin alegría- esto nos puede interesar ya que "calle sin alegría" en alemán es «Freudlosse Gasse » es decir la calle "sin Freud"».

Este film que trata sobre una cura analítica se titula Gebeimnisse einer Seele ( Secretos de un alma»). El término alma en alemán no es tan metafísico, designa el sello del espíritu o del andamiaje del espíritu. Pabst filma con Werner Krauss (actor del Gabinete del Dr. Caligari de R. Wiene y de Tartufo de Murnau; Jean Renoir iba a contratarlo para filmar Nana el año siguiente). Krauss, así como Pabst, resulta sumamente seducido por el nazismo. Quien tomó en serio lo que se podría decir esta

\footnotetext{
douvilleolivier@noos.fr
} 
desviación terrorífica y abominable de Werner Krauss y de Pabst hacia el nazismo es el gran sociólogo Kracauer, quien escribió un texto cuya lectura les aconsejo: «De Caligari a Hitler». Allí intenta comprender las desviaciones en una época donde los términos como sueño y mito resultan auténticamente freudianos, el mito o la novela del neurótico, el sueño, la interpretación de los sueños, el mito de la Alemania nazi, el sueño de los pueblos, etc.

Una película muda, que fue en ocasiones titulada $E n$ el umbral del dormitorio relata una cura psicoanalítica centrada en la interpretación de los sueños. Fue realizada con la colaboración científica de K. Abraham y H. Sachs, y dirigida con el financiamiento de Goldwyn. La historia narra la aparición de síntomas neuróticos en Martin Fellman, químico, casado y burgués interpretado por Werner Krauss. Pesadillas, sueños, fantasías de asesinato de su mujer y un fuerte sentimiento de culpa paralizan su existencia hasta que conoce un psicoanalista, el Dr. Ott, interpretado par Pavel Pavlov que, a través de la cura psicoanalítica, alcanzará a curarlo. Si las escenas oníricas pueden remitir a las tendencias expresionistas, este film se inscribe firmemente, como el arte de Pabst, en un intento de escenificar la vida cotidiana de manera realista.

El proyecto de filmar una cura suscita las más vivas reticencias de la parte de Freud, quien considera imposible «presentar sus teorías abstractas bajo la forma plástica de un film» al igual que otros analistas, entre ellos Bernfeld y Storfer.

El estreno de En el umbral del dormitorio tuvo lugar a fines del año anterior en presencia de Eitigon, Ferenczi y Jones, quien se equivoca y para complacer a Freud, habla de una gran consternación causada por este espectáculo. Sin embargo, el film fue muy aplaudido en el estreno, el 25 de marzo. Y, además, fue elogiado a través de una acogida crítica totalmente a favor ( $«$ Es un estudio psicológico extraordinario, autentico en todos los aspectos, caracterizado de una manera estupenda » le Deutsche Tageszeitung, 25 de marzo, «Un sujeto de rigurosa actualidad: la teoría psicoanalítica de Freud puede volverse popular gracias al cine... Se facilitó la comprensión de qué es una pulsión reprimida, una representación obsesiva, cómo el método de tratamiento, el psicoanálisis, opera.» Berliner Börsen-Courier, 27 de marzo). Hostil a este film que juzga como peligroso para la reputación del psicoanálisis, Jones no dirá ni una palabra en la biografía, hoy en día anticuada y partidaria, que hizo de Freud. A pesar de sus reticencias respecto de la filmación de un análisis psicoanalítico y convencido que el film de Pabst era un fracaso, Bernfeld se asocia con Storfe para propo- ner otro film cuyo guión («Entwurf zu einer filmischen Darstellung der Freudschen Psychoanalyse im Rahmen eines abendfüllenden Spielfilms ») recién conocerá su presentación en el año 2000. Bernfeld será posteriormente el co-guionista con Artur Semyonovich Berger (18921981) del primer film de Otto Preminger, estrenado en 1931, Die große Liebe («El Gran Amor») que aborda la confusión que una mujer tiene de un soldado que volvió al país considerándolo como su hijo perdido.

El film que nos ocupa fue distribuido con tres títulos: Misterios de un alma, La extraña aventura del doctor Mathias y En el umbral del dormitorio. Freud no queda satisfecho con y critica rudamente a los dos discípulos que participaron de su realización. Las razones de la hostilidad de Freud son totalmente explicables. Considera que filmar una cura analítica reduce el trabajo del sueño a una simple ilustración simbólica y que la causalidad psíquica es presentada de manera mecánica descuidando la complejidad de la causalidad psíquica.

Uno podría lamentar con facilidad la reticencia de Freud quien nunca manifestó curiosidad por las artes que le eran contemporáneas. Nuestra demanda, que puede ser considerada infantil pero que es una demanda verdadera evidentemente, se ubica cuando se le reprocha a Freud de haber sido «has been » en su diálogo con las creaciones culturales de su tiempo. En esto estamos en la estacada ya que la literatura para Freud se detiene antes de Proust y cuando lee una o dos páginas de Proust, se cansa y murmura: «estos franceses tienen frases interminables ». El cine no le interesa; el jazz, la música dodecafónica, menos aún.

Sin embargo, ese desinterés no implica que la metapsicología freudiana no podría tomarle el gusto a las creaciones contemporáneas aun cuando el padre del psicoanálisis, Sigmund Freud, no escuchaba jazz mientras degustaba las producciones de Pabst, o los cuartetos de Schoenberg. No vamos a adoptar la postura de un Onfray colérico melancólico. Lo que resulta interesante es distinguir que la metapsicología de Freud habla de la imagen, habla de los estados del cuerpo, habla de las narrativas cortadas, aun cuando a Freud no le gustaban las imágenes cinematográficas, ni las figuras ondeantes en las desfiguradas languideces proustianas.

Es posible observar que las consideraciones de Freud sobre la imagen, sobre lo que perfora la imagen, sobre la alucinación negativa, son de una cierta importancia para quien intenta captar a qué se opone el cine. Ahí está por lo tanto Freud que dice no tolerar el cine pero señala muy acertadamente que la alucinación que importa para el psicoanalista no es la alucinación que hace ver cosas allí don- 
de no hay nada - definición fastidiosa e incluso ridícula de Esquirol- No, lo que importa en la alucinación es la alucinación negativa. Y solo eso, es algo que nos permite ir hacia los filmes, es decir, considerar tal vez que un film es una máquina que es a la vez notificada de lo qué es la alucinación negativa y que resiste. Propongo considerar que el cine transmite la imagen no sobre un fondo de ausencia de la imagen sino sobre un fondo de deconstrucción de la misma. Ahí tienen ya una indicación.

Una segunda pista que traza Freud es la percepción, sin duda siguiendo lo que señala de la alucinación negativa, pero que le es dividida desde un principio. Esta partición designada desde el famoso pasaje sobre la relación con el otro en «Proyecto de una psicología para neurólogos» de 1895, que se realiza entre lo familiar y lo no familiar, va a perseguir a Freud aun en 1915, 11 años antes del film de Pabst, en «Lo ominoso ». Esta inquietante extrañeza de lo siniestro es la puesta en crisis de todo sujeto en el momento donde el muerto toma el vivo, donde el animado toma el inanimado. Se anida en este texto una reflexión sobre el lugar y el impacto de la muerte y de la desaparición en el yo.

Freud no era partidario del cine, pero las herramientas que nos dejó permiten hablar del cine.

Esto nos permite hacer un pequeño puente con el hecho que los psicoanalistas son bastantes ávidos por el cine, lo que no quiere decir informados. Además, la difusión del cine y la difusión del psicoanálisis, especialmente en los Estados Unidos, originaron productos que materializan la vida psíquica; el cine es una materialización de la vida mental.

Voy a dar un ejemplo muy simple que concierne a lo que nombramos como «flashback». Es una noción que se introdujo en nuestra vida psíquica con el cine y no con la literatura. Si se examinan los relatos de los traumatizados por la guerra de 1914, relatos que fueron analizados incluso por psicoanalistas tales como Rank, Tausk, Abraham, Ferenczi, Simmel o Rivers, uno se da cuenta que no tienen ningún flashback en los traumas de guerra; tienen sideraciones, se encuentran grandes cantidades de terrores nocturnos, pesadillas, pero la idea que vuelve en flashback una secuencia que sería como filmada por el psiquismo no se da ahí. Por lo tanto, el cine tiene una influencia sobre la mentalización, el cine representa una materialización de nuestra vida mental que tiene efectos sobre nuestra propia vida mental. Es un efecto del arte contemporáneo sobre las formas mismas de la vida psíquica.

Por otro lado, la difusión del psicoanálisis en el mundo de la producción cinematográfica no es poca cosa, incluso si se realiza sobre una reducción del psicoanálisis espolvoreada de pociones janetianas. Basta con pensar en Hitchcock, Spellbound, escenificada por Salvador Dalí, basta pensar en el trauma de Marnie, basta pensar en «Rosebud» de Citizen kane. Comparemos extractos, planos de estas películas. Su interés radica en representar este "alrededor" de dónde gira nuestra vida psíquica, es decir una escena a la cual el sujeto no tiene acceso directo.

La difusión de un cierto freudismo ha igualmente influenciado un estilo de film, es muy claro en Welles, es muy claro en Hitchcock.

Lo colectivo aquí insiste. Considerando que ubicamos el cine como aquello que no intenta representar lo irrepresentable sino que está en vías de construcción de una semiótica y de una energía ligada, rindiendo cuenta de este esfuerzo, vemos que el cine en su creación está en contacto directo con lo que compromete el imaginario narrativo. Es de una importancia decisiva para resistir a la negación señalar que hubo un intento de forclusión de lo que hace puente imaginario y simbólico entre los hombres y el mundo en el que habitan, entre los hombres y las esperanzas expectativas que tienen.

No por volver a producir un imaginario narrativo va a sanar su forclusión; sería una lástima analizar los filmes de Orson Welles para un resultado tan patético. Qué decir de la forclusión del imaginario narrativo cuando resuena en las turbulencias del imaginario especular; si hay forclusión del imaginario narrativo, lo que vuelve en primer plano es una especie de locura de identidad, de locura persecutoria por el imaginario especular. Entonces ¿cómo se puede sanar el imaginario especular?

Desarrollaré entonces una tesis que proviene de mis diálogos con Jean-Jacques Moscovitz. Mi propósito no es decir que el psicoanálisis deba aplicarse al cine o que el cine ilumina los conceptos del psicoanálisis, la tesis que defiendo va por fuera de este juego de restitución. Enuncia que en el acto del psicoanalista o en el arte del cineasta hay una fuerza de resistencia al silenciamiento, a la alucinación negativa.

La segunda tesis se basa sobre la idea de que cuando hay una forclusión del imaginario narrativo, no se van a arreglar las cosas refabricando imaginario narrativo, sino reparando lo que puede no ser perceptible en la relación especular. Intentemos hallar una nueva erotización responsable del arte de pensar, del arte de filmar, e incluso del arte de amar.

Traducción: Carolina Kasimierski 